\title{
CONDICIONAMENTO FISIOLÓGICO EM SEMENTES DE COENTRO
}

\author{
Rogério Luciano Severiano ${ }^{1}$, Paloma Rayane Pinheiro ${ }^{1}$, Márcio Dias Pereira ${ }^{1}$ \\ ${ }^{1}$ Universidade Federal do Rio Grande do Norte, E-mail: rogerioagron@live.com, palloma.ana@hotmail.com, \\ marcioagron@yahoo.com.br
}

\section{RESUMO}

O objetivo deste trabalho foi avaliar germinação e desenvolvimento inicial de plântulas de coentro submetidas a três métodos de condicionamento fisiológico por cinco períodos. Houve efeito significativo do método e do tempo de condicionamento para a maioria das variáveis analisadas, sendo o rolo de papel, o que permitiu melhor desempenho de vigor das sementes na maioria dos períodos testados. A germinação e o desenvolvimento inicial das plântulas diminuíram à medida que se aumentou as horas de condicionamento fisiológico.

Palavras-chave: Coriandrum sativum, pré-hidratação, vigor

\section{PRIMING IN CORIANDER SEEDS}

\begin{abstract}
The objective of this study was to evaluate germination and early development of Coriander seedlings subjected to three methods of physiological conditioning for five periods. There was a significant effect of the method and the conditioning time for most of the variables, being the paper roll, the one which allowed better performance of seed vigor in most tested periods. The germination and early seedling development decreased as one increased the hours of priming.
\end{abstract}

Keywords: Coriandrum sativum, prehydration, vigor

\section{INTRODUÇÃO}

O coentro (Coriandrum sativum L.) é uma hortaliça bastante utilizada no Brasil como tempero, desempenhando papel importante na horticultura dos estados que compõem o Norte e o Nordeste brasileiro
(ALVES et al., 2005). Em 2001 o Brasil comercializou 270 toneladas de sementes o que gerou uma receita de 2,7 milhões de reais, porém, embora seja uma espécie de clima tropical, altas temperaturas podem limitar o estabelecimento dessa cultura no campo (PEREIRA et al., 2005). 
Para a maioria das espécies de hortaliças que apresentam ciclo de produção curto, a fase mais crítica é o período entre a semeadura e a emergência das plântulas, assim, a uniformidade e a velocidade de emergência assumem grande importância no rendimento e na qualidade do produto final (PEREIRA et al., 2005). Na cultura do coentro, como em outras hortaliças, justificase a busca por técnicas que acelerem e uniformizem o processo de germinação, visando um rápido estabelecimento no campo (SILVA et al., 2012).

A água é essencial para uma rápida velocidade e bom percentual de germinação. Baixos teores de água reduzem a atividade metabólica da semente, sendo essencial que essa volte a absorvê-la para que os seus processos metabólicos sejam reativados (GUIMARÃES et al., 2008). Poucos são os trabalhos que tratam da entrada de água em sementes de coentro, porém sabe-se durante o processo de germinação, sementes com reservas cotiledonares atingem teores de água superiores a $45 \%$, e que em todas as espécies, os eixos embrionários chegam a atingir mais de $50 \%$ de umidade (MARCOS FILHO, 2005).

O condicionamento fisiológico é uma técnica que tem como objetivo melhorar o desempenho das sementes, uniformizando a velocidade de emergência de plântulas, mesmo quando essas são submetidas a condições adversas (GUIMARÃES et al., 2008). Esta técnica se baseia na embebição das sementes em água, substratos umedecidos, solução osmótica ou salina, para a ativação dos processos metabólicos que ocorrem durante a germinação (ARAÚJO et al., 2011), permitindo assim melhor controle da disponibilidade hídrica. Em seguida, as sementes passam por um processo de secagem ou podem ser imediatamente utilizadas; dessa forma ao final de todo o processo de condicionamento todas as sementes se encontrariam na fase II do processo metabólico de germinação sem alcançar a fase de emissão da raiz primária (fase III) (GURGEL JÚNIOR et al., 2009). Nessa etapa o conteúdo de água na semente tende a se estabilizar devido á proximidade dos potenciais hídricos do substrato e da semente, ocorre então à ativação metabólica de processos pré-germinativos, onde mitocôndrias e enzimas tornam-se funcionais ocorrendo intensa digestão das reservas (GUIMARÃES et al., 2008).

Varias são as técnicas utilizadas para o condicionamento fisiológico, mas o hidrocondicionamento tem algumas vantagens sobre as demais, principalmente pelo material requerido para a sua execução. 
Por ser mais simples e barato, não necessita de reagentes e equipamentos sofisticados, sendo que é afetado por alguns fatores tais como período de tratamento, tamanho das sementes, genótipo, potencial fisiológico inicial das sementes e outros (ARAÚJO et al. 2011).

A eficiência do condicionamento fisiológico foi comprovada em sementes de várias espécies de hortaliças, como pepino (LIMA \& MARCOS FILHO, 2010; GURGEL JÚNIOR et al., 2009), cebola (HOLBIG et al., 2011), couve flor (MARCOS FILHO \& KIKUTI, 2008), pimentão (KIKUTI et al., 2005), berinjela, melancia, melão, tomate (NASCIMENTO, 2005) e cenoura (BALBINOT \& LOPES 2006).

O objetivo deste trabalho foi avaliar germinação e desenvolvimento inicial de plântulas de coentro submetidas a três métodos de condicionamento fisiológico, por cinco períodos.

\section{MATERIAL E MÉTODOS}

O trabalho foi realizado no Laboratório de Análises e Pesquisa em Sementes da Unidade Acadêmica Especializada em Ciências Agrárias da Universidade Federal do Rio Grande do Norte - UAECA/UFRN, no período de janeiro a março de 2015.
Utilizaram-se sementes de coentro cultivar verdão com potencial de germinação estimado em $80 \%$ de acordo com o fabricante, adquiridas no comércio local com umidade inicial de 5,6\%. Utilizou-se amostras de 200 sementes as quais foram submetidas a três métodos de condicionamento: (1) Em caixas do tipo gerbox: as sementes foram mantidas sobre telas de alumínio, fixadas no interior das caixas, sendo adicionados $40 \mathrm{~mL}$ de água destilada no fundo da caixa; (2) Rolo de papel: as sementes foram distribuídas sobre duas folhas de papel germitest ${ }^{\circledR}$ e cobertas por outra folha do mesmo papel que foi umedecido com água destilada na quantidade de três vezes a massa do seu peso seco para formar um rolo (BRASIL, 2009); (3) Imersão em água: as sementes foram imersas dentro de copos descartáveis contendo $60 \mathrm{~mL}$ de água destilada. Os períodos de condicionamento das sementes em todos os métodos testados foram: 0 (testemunha não submetida aos métodos), 2, 4, 6 e 8 h, a uma temperatura constante de $25^{\circ} \mathrm{C}$ em câmaras de germinação do tipo BOD, de acordo com as regras para a análise de sementes (BRASIL, 2009), para o teste de germinação.

Ao completar cada período de condicionamento, as amostras de sementes 
foram retiradas, e em seguida, submetidas aos seguintes testes e avaliações: Teste de germinação - para cada tratamento, utilizaram-se 200 sementes divididas em quatro repetições de 50 e distribuídas sobre duas folhas de papel germitest ${ }^{\circledR}$. O papel foi umedecido com água destilada na quantidade equivalente a três vezes a massa do papel seco. As avaliações foram realizadas diariamente, iniciando-se no primeiro dia após a semeadura e finalizando no décimo dia, considerando como germinadas apenas as plântulas normais (BRASIL, 2009); Primeira contagem de germinação: realizada em conjunto com o teste de germinação, computando-se a porcentagem de plântulas normais obtidas no quinto dia após a semeadura (BRASIL, 2009); Índice de velocidade de germinação: foi determinado mediante contagens diárias, do mesmo horário, do número de sementes germinadas, do primeiro ao décimo dia após a semeadura, cujo índice foi calculado de acordo com a equação proposta por Maguire (1962): $\mathrm{IVG}=\mathrm{G} 1 / \mathrm{N} 1+\mathrm{G} 2 / \mathrm{N} 2+\ldots \mathrm{Gn} / \mathrm{Nn}$, Onde: $\mathrm{G} 1, \mathrm{G} 2, \ldots \mathrm{Gn}=$ número de plântulas normais computadas na primeira contagem, na segunda contagem e na última contagem, e $\mathrm{N} 1, \mathrm{~N} 2, \ldots \mathrm{Nn}=$ número de dias da semeadura à primeira, segunda e última contagem; Comprimento da parte aérea e da raiz primária: após a contagem final do teste de germinação, a parte aérea e a raiz primária das plântulas de cada tratamento foram medidas com auxílio de uma régua graduada em centímetros, sendo os resultados expressos em cm plântula ${ }^{-1}$.

Com o intuito de observar a entrada de água nas sementes por cada um dos métodos de condicionamento utilizado, foram determinadas as curvas de embebição das sementes. Para tal foram utilizadas duas repetições de 30 sementes as quais foram pesadas nos 5 períodos avaliados, por meio de balança analítica de precisão $(0,0001 \mathrm{~g})$.

Utilizou-se o delineamento experimental inteiramente casualizado, em esquema fatorial $3 \times 5$ (condicionamento $\mathrm{x}$ período) com quatro repetições de 50 sementes. Os dados obtidos foram submetidos à análise de variância a 5\% pelo teste $\mathrm{F}$ e, quando significativos, procedeu-se a comparação entre médias (Tukey 5\%), para os dados qualitativos e a análise de regressão, para os quantitativos. O software utilizado na análise foi Statistical Analysis System - SAS (SAS, 1999).

\section{RESULTADOS E DISCUSSÃO}

Registrou-se (Tabela 1) os valores dos resultados de quadrados médios para todas as variáveis analisadas. Não se 
observou interação entre os métodos e os diferentes períodos de condicionamento, sendo os fatores estudados de forma isolada. Foi verificado efeito dos períodos de condicionamento sobre todas as características analisadas. Não foi verificado efeito dos diferentes métodos de condicionamento sobre o comprimento da parte aérea e da raiz, no entanto, resultados significativos foram encontrados para germinação, primeira contagem de germinação e índice de velocidade de germinação.

As curvas de pré-embebição de sementes de coentro nos diferentes substratos foram ilustradas (Figuras 1A, 1B e 1C).

Tabela 1. Resumo da análise de variância para germinação (GER), primeira contagem de germinação (PCG), índice de velocidade de germinação de sementes (IVG), comprimento da parte aérea (CPA) e da raiz (CR) de plântulas provenientes de sementes de coentro submetidas a diferentes métodos e períodos de condicionamento fisiológico. Macaíba-RN, 2015

\section{QM}

FV GL

GER $(\%) \quad$ PCG $(\%) \quad$ IVG $\quad$ CPA $(\mathrm{cm}) \quad$ CR $(\mathrm{cm})$

\begin{tabular}{ccccccc}
\hline Método (M) & 2 & $0,026^{*}$ & $0,114^{*}$ & $15,18^{*}$ & 0,532 & 2,882 \\
Tempo (T) & 4 & $0,064^{*}$ & $0,108^{*}$ & $13,357^{*}$ & $5,923^{*}$ & $5,669^{*}$ \\
M x T & 8 & 0,007 & 0,028 & 2,193 & 0,532 & 0,962 \\
Erro & 45 & 0,006 & 0,033 & 2,601 & 0,49 & 0,912 \\
& & & & & \\
\hline Média & & 0,884 & 0,719 & 10,785 & 6,809 & 6,831 \\
CV $(\%)$ & 0,007 & 0,035 & 2,999 & 0,497 & 0,991 \\
& & & & & \\
\hline
\end{tabular}

(*) significativo a 5\% pelo teste $\mathrm{F}$ 
A.

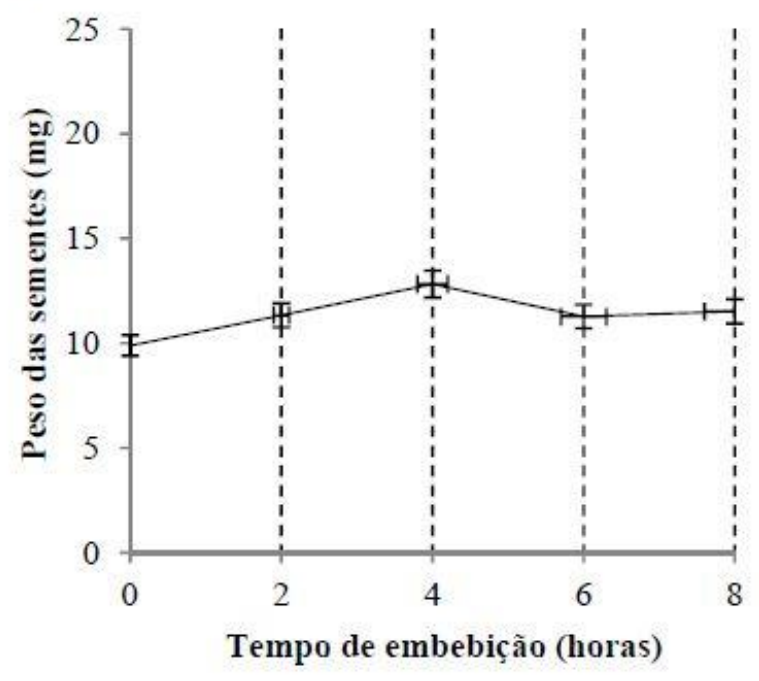

B.

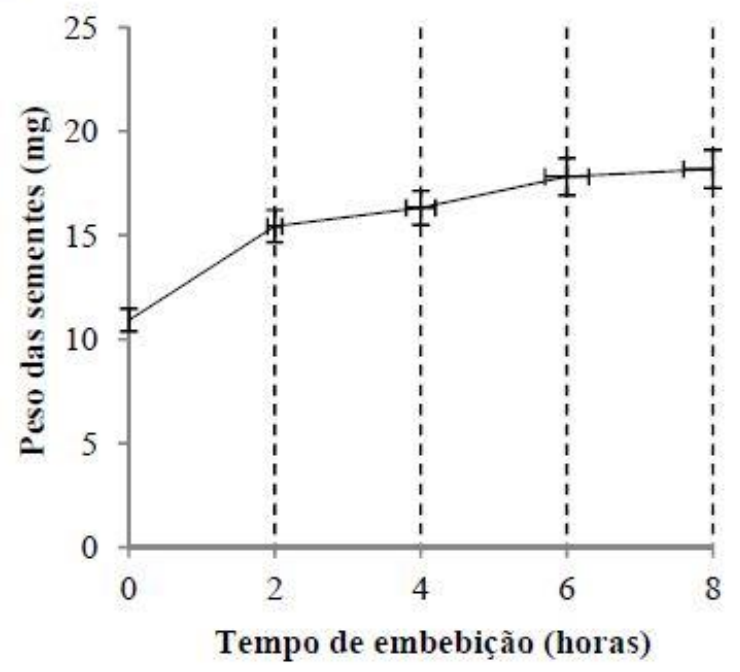

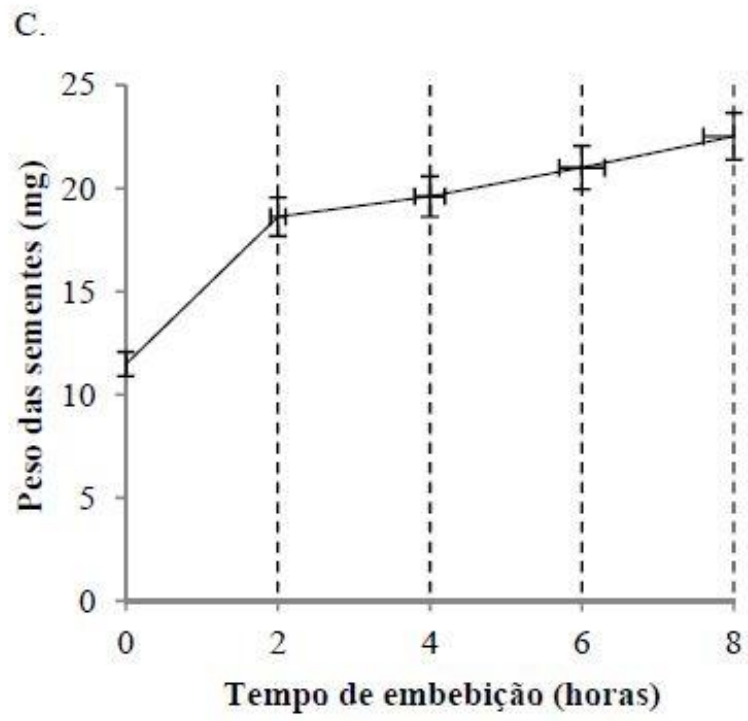

Figura 1. Curva de embebição das sementes de coentro durante o condicionamento fisiológico à $25{ }^{\circ} \mathrm{C}$ em caixa de gerbox (A), rolo de papel (B) e imersão em agua (C) em diferentes períodos. Macaíba-RN, 2015

No método de condicionamento em caixa de gerbox, a fase I se estendeu até as quatro horas de embebição, quando foi verificado um aumento de $29 \%$ do peso inicial das sementes. Nos demais métodos de condicionamento essa fase foi completada já nas primeiras duas horas após o início da embebição, quando as sementes atingiram um incremente de $41 \%$ e $62 \%$ de umidade nos métodos de condicionamento em rolo de papel e imersão em água, respectivamente. Este maior incremento de peso nos métodos de rolo de papel e imersão em água pode ser justificado pelo contato direto das sementes 
com a água, o que não aconteceu no método que utilizou caixas de gerbox.

A fase I de embebição de sementes corresponde à rápida entrada de água, em função da grande diferença do potencial hídrico entre as sementes e o substrato (MARCOS FILHO, 2005). Ao final dessa fase, os potenciais hídricos das sementes endospérmicas atingem graus de umidade de 25 a 30\%, enquanto que sementes cotiledonares chegam a 35 e $40 \%$ de água.

$\mathrm{Na}$ fase II ou fase de ativação metabólica ocorre uma série de eventos prégerminativos e a velocidade de absorção de água se torna mais lenta, devido ao fato do potencial hídrico durante a embebição aumentar, fazendo com que a quantidade de água absorvida pela semente se estabilize. Desta forma os potenciais hídricos do substrato e das sementes ficam muito próximos fazendo com que a mesma chegue ao final com o seu nível de hidratação praticamente igual ao do final da fase I (GUIMARÃES et al., 2008). No método de embebição em caixas de gerbox observou-se que as sementes apresentaram perda de peso em relação ao peso adquirido ao final da fase I, atingindo, ao final das oito horas de embebição, um aumento de peso de $16 \%$ em relação ao inicial. Nos demais métodos, a entrada de água se deu de forma muito lenta, como já previsto pelo padrão trifásico de absorção, ao final das oito horas as sementes que foram submetidas ao método do rolo de papel pesaram $66 \%$ a mais do que o inicial, enquanto que as submetidas ao método da imersão em água $96 \%$.

A fase III caracterizada como a fase de absorção ativa de água e emissão da raiz primária, a qual só ocorre em sementes viáveis e não dormentes, não é observada quando se realiza o condicionamento já que o objetivo desse é a ativação dos processos metabólicos de germinação sem que haja a emissão de raiz primária.

Para a germinação observou-se que o método de condicionamento fisiológico sobre rolo de papel destacou-se diante dos demais, apresentando um maior número de plântulas germinadas (Tabela 2). Considerando as curvas de embebição do presente trabalho, observa-se que esse método apresenta entrada de água de forma intermediária quando comparado com os demais métodos, o que proporciona uma melhor reativação do metabolismo embrionário, no processo de germinação de sementes (COSTA et al., 2008).

Nos resultados dos testes de primeira contagem de germinação e índice de velocidade de germinação, também pode ser observado que o método de 
condicionamento sobre rolo de papel foi o que permitiu melhor desenvolvimento inicial das plântulas, destacando-se novamente quando comparado com os demais métodos. Resultados semelhantes também foram observados por Holbig et al. (2010) em sementes de cebola. Segundo esses autores o fato pode ter ocorrido devido aos processos metabólicos que acontecem durante $\mathrm{o}$ condicionamento, que promovem a indução prolongada de síntese de proteínas, o que favorece o balanço metabólico, gerando incrementos no crescimento das plântulas.

Pôde-se observar que as sementes utilizadas como testemunhas tiveram desempenho germinativo superior a todos os outros tratamentos, apresentando germinação, primeira contagem de germinação e índice de velocidade de germinação, maior do que as sementes submetidas ao condicionamento.

Resultados negativos com o uso do condicionamento também foram observados na germinação e desenvolvimento inicial de plântulas de couve-flor (MARCOS FILHO \& KIKUTI, 2008) e pepino (GURGEL JÚNIOR et al., 2009) porém são necessários mais estudos para explicar os efeitos dessa técnica sobre essas características.

Tabela 2. Germinação, primeira contagem de germinação e índice de velocidade de germinação (IVG) de sementes de coentro submetidas a diferentes métodos e períodos de condicionamento fisiológico. Macaíba-RN, 2015

\begin{tabular}{|c|c|c|c|c|c|}
\hline \multirow{2}{*}{$\begin{array}{l}\text { Método de } \\
\text { embebição }\end{array}$} & \multicolumn{5}{|c|}{ Período de embebição (h) } \\
\hline & 0 & 2 & 4 & 6 & 8 \\
\hline \multicolumn{6}{|c|}{ Germinação (\%) } \\
\hline Caixa Gerbox & $100 \mathrm{a}$ & $82 \mathrm{~b}^{1}$ & $87,5 \mathrm{a}$ & $81 \mathrm{~b}$ & $83 \mathrm{a}$ \\
\hline Rolo de papel & $100 \mathrm{a}$ & $95 \mathrm{a}$ & $90 \mathrm{a}$ & $93 \mathrm{a}$ & $85 \mathrm{a}$ \\
\hline Imersão em água & $100 \mathrm{a}$ & $88 \mathrm{a}$ & $87,5 \mathrm{a}$ & $81,5 \mathrm{~b}$ & $72 b$ \\
\hline \multicolumn{6}{|c|}{ Primeira contagem de germinação (\%) } \\
\hline Caixa Gerbox & $88 \mathrm{a}$ & $59 \mathrm{~b}$ & $60 \mathrm{a}$ & $65 \mathrm{~b}$ & $71 \mathrm{a}$ \\
\hline Rolo de papel & $88 \mathrm{a}$ & $82 \mathrm{a}$ & $76 \mathrm{a}$ & $84 \mathrm{a}$ & $73 \mathrm{a}$ \\
\hline Imersão em água & $88 \mathrm{a}$ & $74 \mathrm{a}$ & $63 \mathrm{a}$ & $60 \mathrm{~b}$ & $47 \mathrm{~b}$ \\
\hline \multicolumn{6}{|c|}{ IVG } \\
\hline Caixa Gerbox & $12,59 \mathrm{a}$ & $8,9 \mathrm{~b}$ & $8,9 \mathrm{~b}$ & $9,9 \mathrm{~b}$ & $10,8 \mathrm{a}$ \\
\hline Rolo de papel & $12,59 \mathrm{a}$ & $11,2 \mathrm{a}$ & $11,7 \mathrm{a}$ & $12,2 \mathrm{a}$ & $11,2 \mathrm{a}$ \\
\hline Imersão em água & $12,59 \mathrm{a}$ & $9,8 \mathrm{~b}$ & $9,8 \mathrm{~b}$ & $10,1 \mathrm{~b}$ & $9,3 \mathrm{~b}$ \\
\hline
\end{tabular}

${ }^{1}$ Médias seguidas pela mesma letra na coluna, não diferem entre si pelos teste de Tukey a $5 \%$ de probabilidade 
Dentre os métodos utilizados o condicionamento sobre rolo de papel foi a que mais se destacou diante das demais, para as variáveis comprimento de parte aérea e comprimento de raiz. No entanto não foram observados resultados significativos para essas variáveis. Porém o efeito benéfico do condicionamento sobre o crescimento inicial de plântulas vem sendo relatado na literatura, isso se deve a balanços metabólicos que o condicionamento promove durante a germinação, e que podem não favorecer a mesma, mas geram incrementos favoráveis no crescimento inicial das plântulas (GURGEL JÚNIOR et al., 2009).

Para o fator período de embebição, o que se observou foi a redução da germinação à medida em que se aumentou o tempo, em todos os métodos testados (Figura 2A). Isso pode ser caracterizado como dano por embebição, pois quando submetidas de forma rápida a esse processo, não há tempo suficiente para que as membranas celulares voltem do estado gel para o cristalino líquido, o que acarreta sérios danos celulares, prejudicando de forma direta a germinação (COSTA et al., 2008). Observase que as sementes condicionadas em rolo de papel apresentaram desempenho superior aos demais tratamentos, o que pode levar a entender que os danos causados por esse método de embebição não foram tão prejudiciais quanto os dos demais (Figura 2A).

De forma semelhante à germinação, em todos os métodos testados observou-se que a primeira contagem foi prejudicada com o aumento do tempo de embebição, tendo o método de condicionamento por rolo de papel se destacado diante dos demais, porém esses resultados não superam os do tratamento controle (Figura 2B). Esses efeitos podem ser decorrentes do mesmo processo que prejudicou a germinação, já que essas duas características estão intimamente ligadas. Alguns estudos apontam que a natureza do material de reserva, a diferença no potencial hídrico entre a semente e o meio e a temperatura do ambiente são os três principais fatores que interferem na velocidade de embebição, e que consequentemente pode gerar danos no desempenho germinativo das sementes (GUIMARÃES et al., 2008).

Quando se analisou o índice de velocidade de germinação, observou-se que o desempenho germinativo das sementes, em todos os tratamentos, também foi prejudicado pelo aumento do tempo de embebição (Figura 2C), no entanto não houve prejuízo tão acentuado como nas 
características anteriormente descritas. Resultados semelhantes também foram encontrados em sementes de cebola, onde se observou que os processos metabólicos que ocorrem durante a embebição, podem alcançar níveis que na maioria das espécies não proporcionam incrementos na germinação (HOLBIG et al., 2011).

Ao se avaliar o crescimento inicial de plântulas de coentro submetidas a embebição por diferentes períodos, observou-se que no comprimento de parte aérea, as plântulas provenientes das sementes submetidas ao condicionamento por um curto período de tempo, apresentaram menor desenvolvimento em relação a testemunha e aos tratamentos que passaram por um período de tempo maior de embebição (Figura 2D).

Verificou-se que com aumento do tempo também houve aumento do crescimento de parte aérea das plântulas. Resultados semelhantes foram encontrados em sementes de sementes de cebola, que apresentaram acumulo de matéria seca quando submetidas a embebição em rolo de papel por 24 horas (HOLBIG et al., 2011).
Analisando o comprimento de raiz (Figura 2E), observa-se que em todos os métodos utilizados, as sementes submetidas ao maior tempo de embebição apresentaram melhor desenvolvimento, como também um retardo de crescimento daquelas submetidas a períodos mais curtos.

O maior crescimento de plântulas submetidas a embebição se deve ao fato de processos metabólicos que ocorrem e induzem a síntese de proteínas que levam a um balanço metabólico mais favorável, gerando incrementos no crescimento da plântula (HOLBIG et al., 2011).

É possível observar que algumas características foram afetadas negativamente quando as sementes foram submetidas a períodos curtos de embebição, porém tendem a se recuperar com o aumento do tempo de embebição, o que reforça a hipótese de dano por embebição, sendo algumas características afetadas apenas nas primeiras horas, como ocorreu com o índice de velocidade de germinação e comprimentos de parte aérea e raiz. 

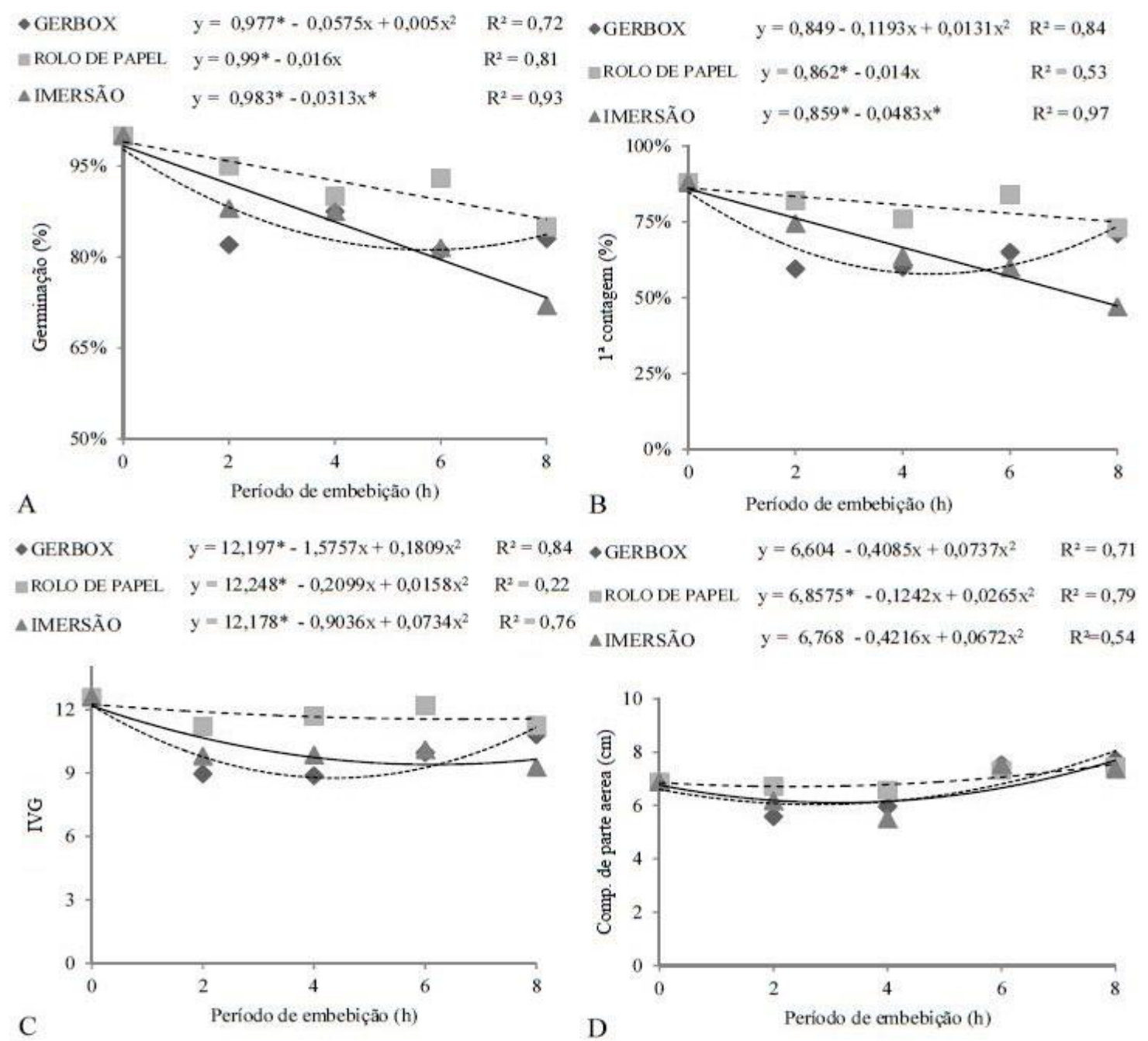

$$
\begin{aligned}
& \text { - GERBOX } \quad \mathrm{y}=6,4031-0,5708 \mathrm{x}+0,0948 \mathrm{x}^{2} \quad \mathrm{R}^{2}=0,65 \\
& \text { = ROLO DE PAPEL } \quad \mathrm{y}=6,7068^{*}-0,0651 \mathrm{x}+0,0238 \mathrm{x}^{2} \quad \mathrm{R}^{2}=0,70 \\
& \triangle \text { IMERSÃO } \quad \mathrm{y}=6,7278^{*}+0,0738 \mathrm{x}+0,0024 \mathrm{x}^{2} \quad \mathrm{R}^{2}=0,27
\end{aligned}
$$

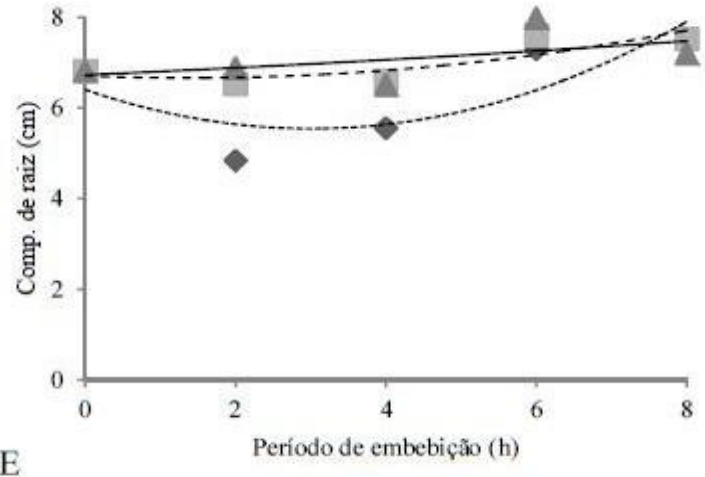

Figura 2. Efeito do aumento do tempo e dos métodos de condicionamento fisiológico sobre a germinação, primeira contagem de germinação, índice de velocidade de germinação, comprimento de parte aérea e comprimento de raiz. Macaíba-RN, 2015 


\section{CONCLUSÕES}

A germinação e o desenvolvimento inicial de plântulas de coentro diminuíram à medida que se aumentou o período de condicionamento fisiológico em todos os métodos, sendo o método de embebição por rolo de papel o mais indicado por ter permitido melhor desenvolvimento inicial das plântulas em relação aos demais métodos.

\section{REFERÊNCIAS}

ALVES, E.U.; OLIVEIRA, A.P.; BRUNO, R. DE L.A.; SADER, R.; ALVES, A.U. 2005. Rendimento e qualidade fisiológica de sementes de coentro cultivado com adubação orgânica e mineral. Revista Brasileira de Sementes, Londrina, v.27, n.1, p.132-137.

ARAÚJO, P.C.; TORRES, S.B.; BENEDITO, C.P.; PAIVA, E.P. 2011. Condicionamento fisiológico e vigor de sementes de maxixe. Revista Brasileira de Sementes, Londrina,v.33, n.3, p.482489.

BALBINOT, E; LOPES, H.M. 2006. Efeitos do condicionamento físiológico e da secagem na germinação e no vigor de sementes de cenoura. Revista Brasileira de Sementes, Londrina, v. 28, n.1, p.0108.

BRASIL. 2009. Regras para análise de Sementes. Ministério da Agricultura, Pecuária e Abastecimento, Brasília, 399 p.

COSTA, C.J.; VILLELA, F.A.; BERTONCELLO, M.R.; TILLMANN, M.Â.A.; MENEZES, N.L. 2008.Pré- hidratação de sementes de ervilha e sua interferência na avaliação do potencial fisiológico. Revista Brasileira de Sementes, Londrina, v.30, n.1, p.198207.

GUIMARÃES, M. A.; DIAS, D.C.F. S.; LOUREIRO, M.E.2008. Hidratação de sementes. Revista Trópica - Ciências Agrárias e Biológicas, Chapadinha,v.2, n.1, p.31-39.

GURGEL JÚNIOR, F.E.; TORRES, S.B.; OLIVEIRA, F.N.; NUNES, T. A.2009. Condicionamento fisiológico de sementes de pepino. Revista Caatinga, Mossoró,v.22, n.4, p. 163-168.

HOLBIG, L. S.; BAUDET, L.; VILLELA, F.A.2011.Hidrocondicionamento de sementes de cebola. Revista Brasileira de Sementes, Londrina,v.33, n.1, p.171176.

KIKUTI, A. L. P.; KIKUTI, H.; MINAMI, K. 2005.Condicionamento fisiológico em sementes de pimentão. Revista Ciência Agronômica, Fortaleza,v.36, n.2, p.243248.

LIMA, L. B.; MARCOS FILHO, J. 2010. Condicionamento fisiológico de sementes de pepino e germinação sob diferentes temperaturas. Revista Brasileira de Sementes, Londrina, v.32, n, 1, p.138147.

MAGUIRE, J.D. Speed of germination-aid in and evaluation for seedling emergence and vigour.1962. Crop Science,London, v.02, n.02, p.176-177.

MARCOS FILHO, J. 2005. Fisiologia de sementes de plantas cultivadas. Fealq, Piracicaba, v 12, 495p.

MARCOS FILHO, J; KIKUTI, A.L.P.2008.Condicionamento fisiológico de sementes de couve-flor e desempenho das plantas em campo. Horticultura Brasileira, Vitoria da Conquista, v.26, n.2, p.165-169.

NASCIMENTO, W. M. 2005. Condicionamento osmótico de sementes de hortaliças visando à germinação em 
condições de temperaturas baixas. Horticultura Brasileira,Vitoria da Conquista, v.23, n.2, p. 211-214.

PEREIRA R.S.; MUNIZ, M.F.B.; NASCIMENTO, W.M. 2005. Aspectos relacionados à qualidade de sementes de coentro. Horticultura Brasileira, Brasília, v.23, n.3, p.703-706.

SAS. 1999. SAS Software. Cary, North Carolina: SAS Institute Inc., 1999.

SILVA, M.A.D.; COELHO JÚNIOR, L.F.; SANTOS, A.P. 2012. Vigor de sementes de coentro (Coriandrum sativum L.) provenientes de sistemas orgânico e convencional. Revista Brasileira de Plantas Medicinais, Botucatu, v.14, n.esp., p.192-196.

Recebido em: 8/4/2015

Aceito para publicação em: 9/3/2016 